\title{
Development and validation of a simple and rapid ICP-OES method for quantification of elemental impurities in voriconazole drug substance
}

\author{
Kishore V. Merusomayajula ${ }^{1,2}\left[\right.$ D, Siva Rao Tirukkovalluri ${ }^{2^{*}}$, Rama Srinivas Kommula', \\ Sathyendranath Venkata Chakkirala', Jagadeesh Kumar Vundavilli ${ }^{1}$ and Pavan Kumar S. R. Kottapalli ${ }^{1}$
}

\begin{abstract}
Background: The aim of the present study was to develop and validate an inductively coupled plasma optical emission spectroscopic (ICP-OES) method for quantification of elemental impurities, i.e., Lead, Palladium, and Zinc, in voriconazole drug substance, and this method was employed for the regular sample analysis of Lead, Palladium, and Zinc in voriconazole drug substance for pharmaceutical use. The method has been validated using RF power of $1150 \mathrm{~W}$, auxiliary gas of $0.5 \mathrm{~L} / \mathrm{min}$, and nebulizer flow of $0.4 \mathrm{~L} / \mathrm{min}$ and plasma view at axial mode for Lead and Palladium and radial mode for Zinc. The wavelength was monitored for Lead, Palladium, and Zinc at $220.3 \mathrm{~nm}$, $340.4 \mathrm{~nm}$, and $213.8 \mathrm{~nm}$ respectively.
\end{abstract}

Results: The method is selective and is capable of detecting desired elemental impurities with regulatory acceptance limits in the presence of other elements. The validation experiments involve the demonstration of system suitability, specificity, LOD and LOQ, linearity, precision, and accuracy experiments. The linearity results obtained ' 0.9990 for all three impurities.

Conclusion: The proposed method is simple, sensitive quality control tool for the simultaneous quantitative determination of Lead, Palladium, and Zinc at low levels in voriconazole drug substance.

Keywords: Inductively coupled plasma optical emission spectroscopy, Pharmaceutical analysis, Elemental impurities, Voriconazole and method validation

\section{Background}

Voriconazole is a second-generation triazole antifungal agent used to treat serious fungal infections. Chemically, voriconazole is $(\alpha R, \beta S)$ - $\alpha$-(2,4-difluorophenyl)-5-fluoro- $\beta$ methyl- $\alpha$-(1H-1,2,4-triazol-1-ylmethyl)-4-pyrimidineethanol (OR) (2R,3S)-2-(2,4-difluorophenyl)-3-(5-fluoropyrimidin4-YL)-1-(1H-1,2,4-triazol-1-YL) butan-2-OL with a molecular formula of $\mathrm{C}_{16} \mathrm{H}_{14} \mathrm{~F}_{3} \mathrm{~N}_{5} \mathrm{O}$ and a molecular weight of

\footnotetext{
* Correspondence: sivaraotvalluri.16@gmail.com

${ }^{2}$ Department of Inorganic and Analytical Chemistry, AU College of Science and Technology, Andhra University, Visakhapatnam, Andhra Pradesh 530003, India

Full list of author information is available at the end of the article
}

349.3 [1]. Voriconazole was first synthesized by Pfizer in the brand name of $\mathrm{Vfend}^{\circ}$ which has broad-spectrum activity against pathogenic yeasts, including Aspergillums, Cryptococcus, and Candida species and ineffective against Rhizopus, Zygomycosis reduced activity [2, 3]. Pharmaceutically, voriconazole formulations are available in both oral and intravenous administration. The similar drug of Fluconazole structurally modified to develop the Voriconazole [4]. In the literature, a few analytical methods have been reported for the quantitative estimation of voriconazole in pharmaceutical dosage form and in biological fluids [5-8], electrophoresis and chromatographic separation of voriconazole stereoisomers [9], determination 
of voriconazole impurities by HPLC [10], and determination of voriconazole in formulation by HPLC [11]. Quantitative determination of voriconazole in rat and beagle dog plasma reported [12]. In voriconazole, synthetic process Lead, Palladium, and Zinc-related complex molecules are used as catalytic agents. During the synthesis of drug substances, elemental impurities may arise from several sources and may be catalysts that were added intentionally in synthesis or may be present as impurities. These elemental impurities do not provide any therapeutic benefit to the patient, and levels in the drugs should be controlled within acceptable limits. Depending upon their permitted daily exposures, lower levels have to be considered for elemental risk [13]. The intake of palladium causes fever, hemolysis, erythema, edema, and eye irritation [14]. Lead causes depression, loss of appetite, intermittent abdominal pain, nausea, diarrhea, constipation, muscle pain, and problems with sleep [15]. Zinc causes nausea, vomiting, loss of appetite, stomach cramps, diarrhea, and headaches [16]. Hence, residual elemental impurities controls are required in voriconazole drug substance for regulatory requirements. Several colorimetric and spectrometric methods for determination of Lead [17-19], Palladium [20-23], and Zinc [24-28] was reported. In view of this, we have developed and validated the inductively coupled plasma optical emission spectroscopy (ICP-OES) method and presented in this research paper. To the best of our knowledge, no method for the determination of Palladium, Lead, and Zinc by ICP-OES was reported in voriconazole drug substance. The developed method was validated according to International Conference on Harmonization (ICH) (Q2A) guidelines [29]. The chemical structure of voriconazole is shown in Fig. 1.

\section{Methods}

\section{Chemicals and reagents}

Sulfuric acid, hydrochloric acid, and hydrogen peroxide purchased were from Merck chemicals limited. ICP standards, Lead, Zinc, and Palladium each $1000 \mathrm{mg} / \mathrm{L}$ and multi-element standard solution IV (1000 mg/L) were purchased from Sigma-Aldrich. Voriconazole working standard was gifted from APL Research Centre-II (a division of Aurobindo Pharma Limited) and Milli Q-water produced from Milli pore water system. Borosil type glassware and calibrated $100-1000 \mu \mathrm{l}$ pipettes were used.

\section{Equipment}

An inductively coupled plasma system equipped with optical emission spectrophotometer make Thermo Fisher Scientific with data handling system controlled with iTEVA software used for method development and validation.

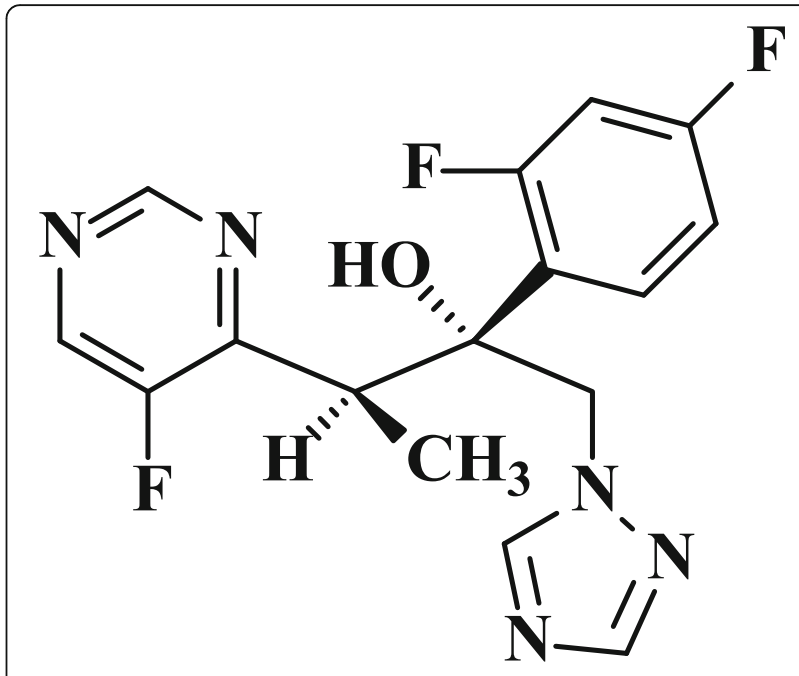

Fig. 1 Chemical structure of voriconazole

\section{Preparation of solutions \\ Lead and Palladium standard stock solution (Pb: 5 ppm and Pd: 10 ppm)}

Fifty microliters of Lead ICP standard solution (1000 $\mathrm{mg} / \mathrm{L})$ and $100 \mu \mathrm{l}$ of Palladium ICP standard solution $(1000 \mathrm{mg} / \mathrm{L})$ was transferred into a $10 \mathrm{ml}$ clean dry volumetric flask, mixed, and made up to volume with MilliQ Water.

\section{Preparation of calibration standard-1 (Lead: 0.015 ppm, Palladium: 0.03 ppm, and Zinc: 3.9 ppm)}

Seventy-five microliters of Lead and Palladium standard stock solution and $97.5 \mu \mathrm{l}$ of Zinc ICP standards $(1000 \mathrm{mg} / \mathrm{L})$ pipette into a $25 \mathrm{ml}$ clean dry volumetric flask, containing $15 \mathrm{ml}$ of water, $2.5 \mathrm{ml}$ of Hydrogen peroxide solution, $1.0 \mathrm{ml}$ of Hydrochloric acid, and slowly $0.5 \mathrm{ml}$ of sulfuric acid was added. The solution was and diluted to the mark with Milli-Q water.

\section{Calibration standard-2 (Lead: 0.03 ppm, Palladium: 0.06 ppm, and Zinc: 7.8 ppm)}

One hundred fifty microliters of Lead and Palladium standard stock solution and $195 \mu \mathrm{l}$ of Zinc ICP standards $(1000 \mathrm{mg} / \mathrm{L})$ were mixed into a $25 \mathrm{ml}$ clean dry

Table 1 Specificity experiments

\begin{tabular}{llll}
\hline $\begin{array}{lll}\text { Elemental } \\
\text { impurity }\end{array}$ & \multicolumn{2}{l}{ Mean value of element $(\boldsymbol{\mu g} / \mathbf{g})$} & $\begin{array}{l}\% \\
\text { Difference }\end{array}$ \\
\cline { 2 - 3 } & Controlled sample & Spiked sample & \\
\hline Lead & 0.55 & 0.55 & 0.0 \\
Palladium & 0.91 & 0.84 & 8.0 \\
Zinc & 128.0 & 125.9 & 1.7 \\
\hline
\end{tabular}


Table $2 \mathrm{LOD}$ and $\mathrm{LOQ}$ prediction

\begin{tabular}{|c|c|c|c|c|c|c|}
\hline \multicolumn{7}{|l|}{ LOD and LOQ prediction } \\
\hline \multirow[t]{2}{*}{ S. No } & \multicolumn{2}{|l|}{ Lead } & \multicolumn{2}{|l|}{ Palladium } & \multicolumn{2}{|l|}{ Zinc } \\
\hline & Conc (ppm) & Counts/S & Conc (ppm) & Counts/S & Conc (ppm) & Counts/S \\
\hline 1 & 0.00501 & 16.435 & 0.01001 & 84.239 & 1.0000 & 232.94 \\
\hline 2 & 0.01001 & 31.430 & 0.02002 & 203.890 & 2.0000 & 453.07 \\
\hline 3 & 0.01502 & 46.324 & 0.03003 & 287.300 & 3.9000 & 872.50 \\
\hline 4 & 0.02002 & 69.326 & 0.04004 & 393.450 & 5.9200 & 1349.10 \\
\hline 5 & 0.03003 & 99.411 & 0.06006 & 575.420 & 7.8000 & 1747.00 \\
\hline 6 & 0.04505 & 151.640 & 0.09009 & 881.090 & 11.7200 & 2665.10 \\
\hline 7 & 0.06006 & 206.010 & 0.12012 & 1180.900 & 15.6000 & 3583.00 \\
\hline STEYX & 2.269403105 & & 8.707586102 & & 18.37286651 & \\
\hline \multirow[t]{2}{*}{ Conc (ppm) } & LOD & LOQ & LOD & LOQ & LOD & LOQ \\
\hline & 0.005 & 0.015 & 0.010 & 0.030 & 0.300 & 1.000 \\
\hline LOD (ppm) w.r.st test conc & 0.08 & & 0.20 & & 5.00 & \\
\hline LOQ (ppm) w.r.st Test conc & 0.25 & & 0.50 & & 16.70 & \\
\hline
\end{tabular}

volumetric flask, containing $15 \mathrm{ml}$ of water, $2.5 \mathrm{ml}$ of hydrogen peroxide solution, $1.0 \mathrm{ml}$ of hydrochloric acid, and slowly $0.5 \mathrm{ml}$ of sulfuric acid was added. The solution was mixed and diluted to the mark with Milli-Q water.

Calibration standard-3 (Lead: 0.06 ppm, Palladium: 0.12 ppm, and Zinc: 15.6 ppm)

Three hundred microliters of Lead and Palladium standard stock solution and $390 \mu \mathrm{l}$ of Zinc ICP standards $(1000 \mathrm{mg} / \mathrm{L})$ were mixed into a $25 \mathrm{ml}$ clean, dry volumetric flask, containing $15 \mathrm{ml}$ of water, 2.5 $\mathrm{ml}$ of hydrogen peroxide solution, $1.0 \mathrm{ml}$ of hydrochloric acid, and slowly $0.5 \mathrm{ml}$ of sulfuric acid was added. The solution was mixed and diluted to the mark with Milli-Q water.

Table 3 LOD and LOQ experiments of Lead

\begin{tabular}{lll}
\hline LOD and LOQ of Lead & & \\
\hline S. No & LOD (ppm) & LOQ (ppm) \\
\hline 1 & 0.0045 & 0.0140 \\
2 & 0.0042 & 0.0132 \\
3 & 0.0045 & 0.0144 \\
4 & 0.0043 & 0.0143 \\
5 & 0.0042 & 0.0132 \\
6 & 0.0040 & 0.0135 \\
Mean & 0.0043 & 0.0138 \\
\%RSD & 4.7 & 3.6 \\
con., (ppm) & 0.005 & 0.015 \\
conc., (ppm) w.r.t test concentration & 0.08 & 0.25 \\
\hline
\end{tabular}

\section{Blank solution}

Transferring $5.0 \mathrm{ml}$ of hydrogen peroxide solution into a $50 \mathrm{ml}$ clean dry volumetric flask, containing $30 \mathrm{ml}$ of water, add $2.0 \mathrm{ml}$ of hydrochloric acid and slowly $1.0 \mathrm{ml}$ of sulfuric acid was added. The solution was mixed and diluted to the mark with Milli-Q water.

\section{Sample solution}

Accurately weighed and transferred about $0.6 \mathrm{~g}$ of sample in to $10 \mathrm{ml}$ clean dry volumetric flask, $1.0 \mathrm{ml}$ of hydrogen peroxide solution, $0.4 \mathrm{ml}$ of hydrochloric acid was added, and sonicate to dissolve. Then, $0.2 \mathrm{ml}$ of sulfuric acid was slowly added, mixed well, and make up to volume with Milli-Q water. (To obtain the clear solutions, centrifuge the sample solutions at $6000 \mathrm{rpm}$ for 10

Table 4 LOD and LOQ experiments of Palladium

\begin{tabular}{lll}
\hline LOD and LOQ of Palladium & & \\
\hline S. No & LOD(ppm) & LOQ(ppm) \\
\hline 1 & 0.0105 & 0.0302 \\
2 & 0.0101 & 0.0301 \\
3 & 0.0109 & 0.0296 \\
4 & 0.0113 & 0.0297 \\
5 & 0.0108 & 0.0299 \\
6 & 0.0111 & 0.0301 \\
Mean & 0.0108 & 0.0299 \\
\%RSD & 3.7 & 0.7 \\
Con., (ppm) & 0.01 & 0.03 \\
conc., (ppm) w.r.t test concentration & 0.2 & 0.5 \\
\hline
\end{tabular}


Table $\mathbf{5} L O D$ and $L O Q$ experiments of Zinc

\begin{tabular}{lll}
\hline LOD and LOQ of Zinc & & \\
\hline S. No & LOD (ppm) & LOQ (ppm) \\
\hline 1 & 0.3092 & 1.0000 \\
2 & 0.3036 & 0.9992 \\
3 & 0.3008 & 1.0060 \\
4 & 0.3011 & 0.9972 \\
5 & 0.3093 & 1.0080 \\
6 & 0.3063 & 1.0030 \\
Mean & 0.3051 & 1.0022 \\
\%RSD & 1.2 & 0.4 \\
Con., (ppm) & 0.3 & 1.0 \\
Conc., (ppm) w.r.t test concentration & 5.0 & 16.7 \\
\hline
\end{tabular}

min and the same solutions are used for sample analysis).

\section{Method development and optimization of conditions}

The principal goal of our research study is to develop an accurate and precise ICP-OES method to quantify Lead, Palladium, and Zinc present in voriconazole drug substance. During the development of the method, Lead, Palladium, and Zinc standard solution of known concentration was monitored for different emission lines 217.0 $\mathrm{nm}, 220.3 \mathrm{~nm}, 216.4 \mathrm{~nm}$, and $283.3 \mathrm{~nm}$ for Lead; 340.4 $\mathrm{nm}, 363.4 \mathrm{~nm}$, and $324.2 \mathrm{~nm}$ for Palladium; and 206.2 $\mathrm{nm}, 213.8 \mathrm{~nm}$, and $202.5 \mathrm{~nm}$ for Zinc respectively by aspirating the solution. The responses of Lead, Palladium, and Zinc are very prominent at $220.3 \mathrm{~nm}, 340.4 \mathrm{~nm}$, and $213.8 \mathrm{~nm}$ respectively when applied the target power of RF 1150W. No possible inferences were observed at this emission lines and good baseline was observed than other wavelengths. During the method development, above said wavelengths were optimized to get better sensitivity. Axial view was used for Lead and Palladium and radial view for Zinc. Instrumental settings are given below.

\section{Source settings}

\begin{tabular}{lll}
\hline Nebulizer pump & Flush pump rate(rpm): & 100 \\
& Analysis pump rate(rpm): & 50 \\
& Pump relaxation time: & $5 \mathrm{~s}$ \\
& Pump tubing type : & Tygon orange/white \\
& $1150 \mathrm{~W}$ & \\
RF power: & $0.5 \mathrm{~L} / \mathrm{min}$ & \\
Auxiliary gas: & $0.40 \mathrm{~L} / \mathrm{min}$ \\
Nebulizer gas flow: & $220.3 \mathrm{~nm}$ for Lead \\
Wavelength & $340.4 \mathrm{~nm}$ for Palladium \\
& $213.8 \mathrm{~nm}$ for Zinc \\
\hline
\end{tabular}

Table 6 Summery of LOD and LOQ experiments results

\begin{tabular}{|c|c|c|c|c|}
\hline \multirow{2}{*}{$\begin{array}{l}\text { Elemental } \\
\text { impurity }\end{array}$} & \multicolumn{2}{|c|}{$\%$ RSD } & \multirow{2}{*}{$\begin{array}{l}\text { LOD } \\
(\mu \mathrm{g} / \\
\mathrm{g})\end{array}$} & \multirow{2}{*}{$\begin{array}{l}\text { LOQ } \\
(\mu \mathrm{g} / \\
\mathrm{g})\end{array}$} \\
\hline & $\overline{L O D}$ & LOQ & & \\
\hline Lead & 4.7 & 3.6 & 0.08 & 0.25 \\
\hline Palladium & 3.7 & 0.7 & 0.2 & 0.5 \\
\hline Zinc & 1.2 & 0.4 & 5.0 & 16.7 \\
\hline
\end{tabular}

\section{Results \\ Method validation Specificity}

To demonstrate specificity of test sample (control sample) and test sample spiked with multi elements, including Lead, Palladium, and Zinc standard (spiked sample) in triplicate were aspirated as per ICP-OES test methodology and determine the Lead, Palladium, and Zinc contents. Acceptance criteria is \% difference between mean of each content in control sample and spiked sample should be not more than $10.0 \%$ as per method validation protocol. The specificity results are tabulated below (Table 1).

\section{$\angle O D$ and $L O Q$}

Limit of detection (LOD) was obtained by aspirating a linear series of Lead 0.005 to $0.06 \mathrm{ppm}$, Palladium 0.01 to $0.12 \mathrm{ppm}$, and Zinc 1.0 to $15.6 \mathrm{ppm}$ standard solutions were prepared in seven concentration ranges

Table 7 Linearity experiment results

\begin{tabular}{|c|c|c|c|c|}
\hline S. No & Conc (ppm) & Counts/S & Statistical analysis & \\
\hline \multicolumn{5}{|c|}{ Results for Lead } \\
\hline 1 & 0.0150 & 55.73 & Slope & 3833 \\
\hline 2 & 0.0224 & 83.63 & Intercept & -2 \\
\hline 3 & 0.0300 & 113.39 & STEYX & 2 \\
\hline 4 & 0.0450 & 167.83 & Correlation co-efficient & 0.9995 \\
\hline 5 & 0.0600 & 229.23 & & \\
\hline \multicolumn{5}{|c|}{ Results for Palladium } \\
\hline 1 & 0.0300 & 245.30 & Slope & 7546 \\
\hline 2 & 0.0448 & 356.00 & Intercept & 13 \\
\hline 3 & 0.0601 & 455.33 & STEYX & 10 \\
\hline 4 & 0.0901 & 685.07 & Correlation co-efficient & 0.9990 \\
\hline 5 & 0.1201 & 927.37 & & \\
\hline \multicolumn{5}{|c|}{ Results for Zinc } \\
\hline 1 & 1.0000 & 24.675 & Slope & 24 \\
\hline 2 & 3.9000 & 94.506 & Intercept & 0 \\
\hline 3 & 7.8000 & 190.24 & STEYX & 3 \\
\hline 4 & 11.7200 & 278.93 & Correlation co-efficient & 0.9997 \\
\hline 5 & 15.6000 & 379.17 & & \\
\hline
\end{tabular}




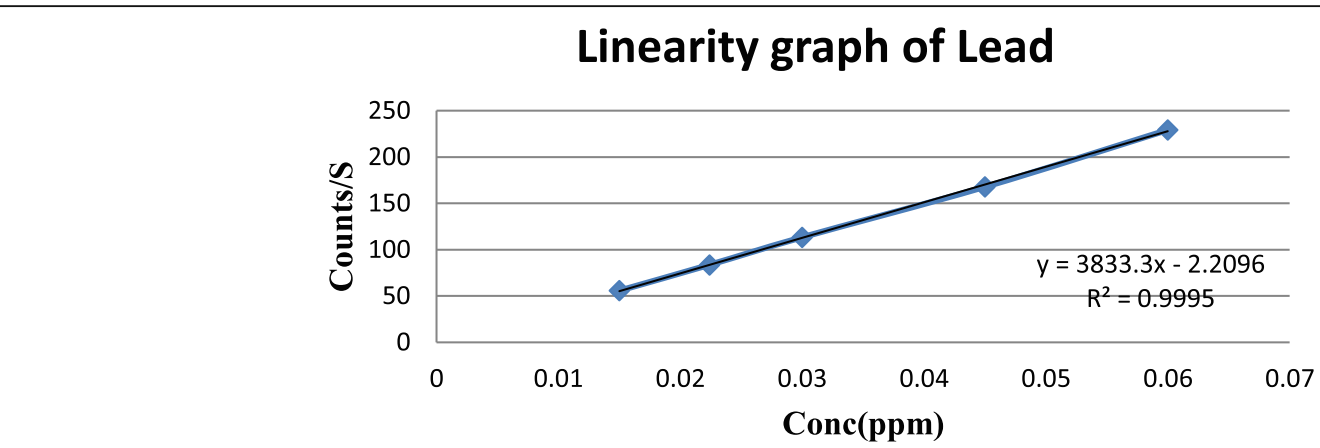

Fig. 2 Linearity graph of Lead

\section{Linearity graph of Palladium}

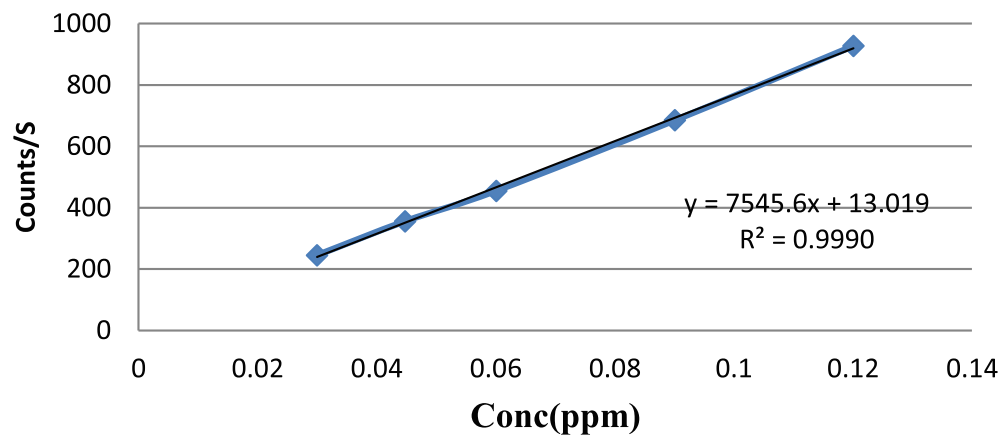

Fig. 3 Linearity graph of Palladium

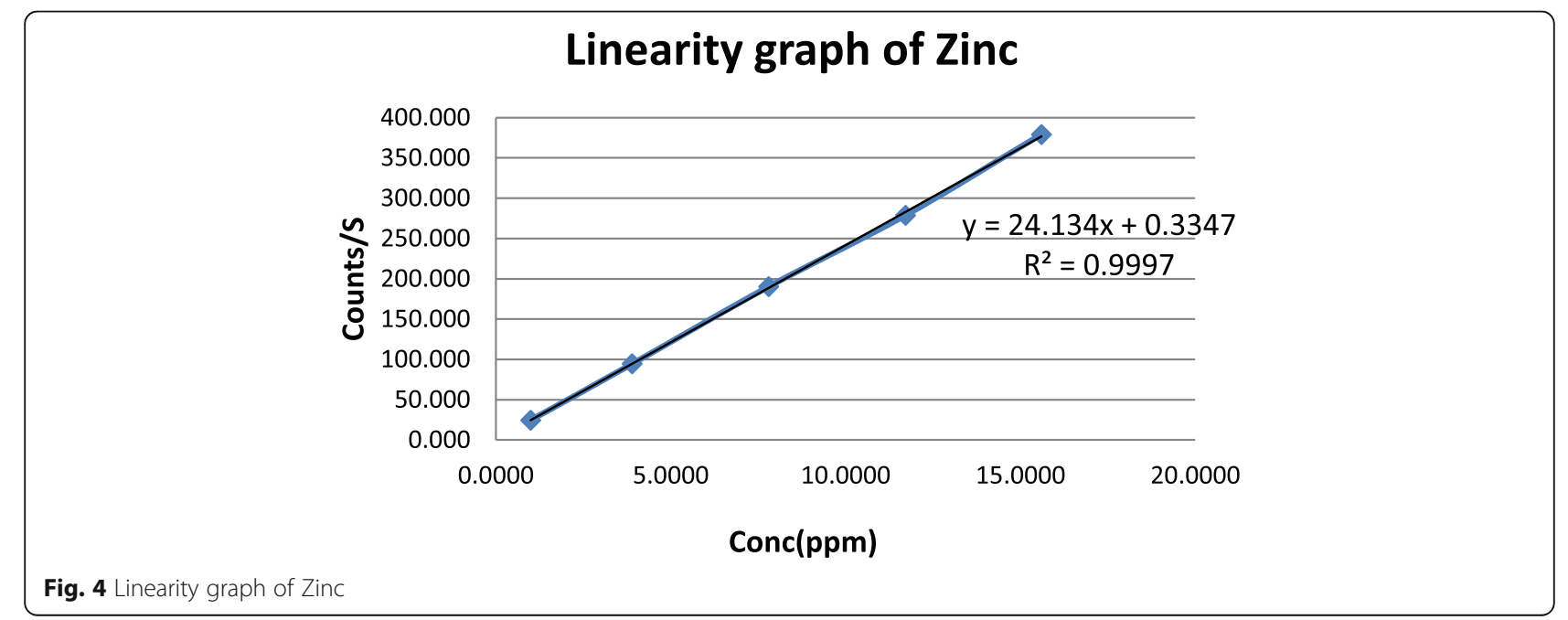


Table 8 Accuracy results for Lead, Palladium, and Zinc

\begin{tabular}{|c|c|c|c|}
\hline \multicolumn{2}{|l|}{ Concentration/sample ID } & Mean \% recovery (triplicate injections each) & $\% \mathrm{RSD}$ \\
\hline \multicolumn{4}{|l|}{ Results for Lead } \\
\hline \multicolumn{2}{|l|}{ LOQ level sample } & 102.8 & 0.3 \\
\hline \multicolumn{2}{|l|}{$50 \%$ level sample } & 108.0 & 0.0 \\
\hline \multicolumn{2}{|l|}{ 100\% level sample } & 110.0 & 1.8 \\
\hline \multicolumn{2}{|l|}{ 150\% level sample } & 112.0 & 1.2 \\
\hline \multicolumn{4}{|l|}{ Results for Palladium } \\
\hline \multicolumn{2}{|l|}{ LOQ level sample } & 85.3 & 1.4 \\
\hline \multicolumn{2}{|l|}{$50 \%$ level sample } & 85.3 & 1.4 \\
\hline \multicolumn{2}{|l|}{ 100\% level sample } & 91.3 & 7.0 \\
\hline \multicolumn{2}{|l|}{$150 \%$ level sample } & 87.6 & 6.2 \\
\hline \multicolumn{4}{|l|}{ Results for Zinc } \\
\hline \multicolumn{2}{|l|}{ LOQ level sample } & 102.8 & 0.3 \\
\hline \multicolumn{2}{|l|}{$50 \%$ level sample } & 100.9 & 3.2 \\
\hline \multicolumn{2}{|l|}{$100 \%$ level sample } & 98.6 & 1.6 \\
\hline \multicolumn{2}{|l|}{ 150\% level sample } & 96.3 & 0.2 \\
\hline \multicolumn{4}{|l|}{ Results of system precision } \\
\hline Repetitions & Lead $(\mathrm{mg} / \mathrm{mL})$ & Palladium (mg/mL) & Zinc $(\mathrm{mg} / \mathrm{mL})$ \\
\hline 1 & 0.0140 & 0.0302 & 1.0000 \\
\hline 2 & 0.0132 & 0.0301 & 0.9992 \\
\hline 3 & 0.0144 & 0.0296 & 1.0060 \\
\hline 4 & 0.0143 & 0.0297 & 0.9972 \\
\hline 5 & 0.0132 & 0.0299 & 1.0080 \\
\hline 6 & 0.0135 & 0.0301 & 1.0030 \\
\hline$\%$ RSD & 3.6 & 0.7 & 0.4 \\
\hline
\end{tabular}

Table 10 Method precision and ruggedness results

\begin{tabular}{lllllll}
\hline $\begin{array}{l}\text { Results for method precision and ruggedness } \\
\text { Sample } \\
\text { preparations }\end{array}$ & $\begin{array}{l}\text { Method precision } \\
\text { Lead }(\boldsymbol{\mu g} / \mathbf{g})\end{array}$ & Ruggedness & $\begin{array}{l}\text { Method precision } \\
\text { Palladium }(\boldsymbol{\mu g} / \mathbf{g})\end{array}$ & Ruggedness & $\begin{array}{l}\text { Method precision } \\
\text { Zinc }(\boldsymbol{\mu g} / \mathbf{g})\end{array}$ \\
\hline 1 & 0.29 & 0.29 & 0.47 & 0.51 & 18.92 & \multicolumn{1}{c}{ Ruggedness } \\
2 & 0.30 & 0.30 & 0.50 & 0.51 & 18.62 & 16.50 \\
3 & 0.31 & 0.29 & 0.48 & 0.48 & 18.40 & 16.69 \\
4 & 0.29 & 0.30 & 0.47 & 0.50 & 17.74 & 16.37 \\
5 & 0.29 & 0.32 & 0.47 & 0.49 & 17.70 & 16.16 \\
6 & 0.29 & 0.30 & 0.46 & 0.47 & 17.67 & 16.56 \\
\%RSD & 2.8 & 3.7 & 2.9 & 3.3 & 3.0 & 16.43 \\
Overall \% RSD & 3.2 & & 3.6 & & 5.7 & 1.1 \\
\hline
\end{tabular}




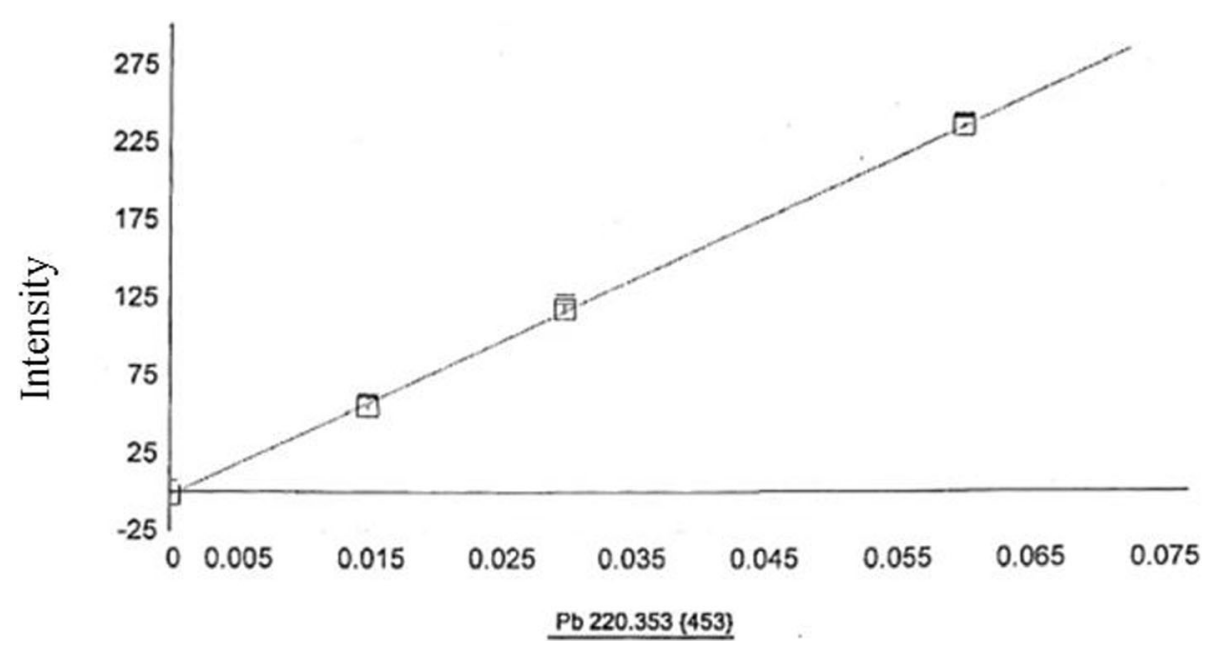

Fig. 5 Method precision representation of Lead

respectively. From the linearity data, slope and residual sum of squares (STEYX) obtained from above LOD and limit of quantitation (LOQ) values were predicted. And acceptance criteria is \%RSD is not more than 33.0 for LOD and 10.0 for LOQ. LOD was calculated as 0.08 ppm for Lead, $0.2 \mathrm{ppm}$ for palladium, and $5.0 \mathrm{ppm}$ for Zinc. LOQ was obtained as $0.25 \mathrm{ppm}$ for Lead, $0.5 \mathrm{ppm}$ for palladium, and $16.7 \mathrm{ppm}$ for Zinc. \% RSD for 6 replicates obtained for LOQ was 3.6\%, $0.7 \%$, and $0.4 \%$ for Lead, Palladium, and Zinc respectively. Summarized results are shown in Tables 2, 3, 4, 5, and 6.

\section{Linearity}

Analytical method linearity is defined as the ability for showing the response of the analyte is proportional to the analyte concentration within a given range. The peak response obtained from the
ICP-OES was plotted against corresponding concentrations to obtain the calibration graph. The results of the linearity study gave linear relationship over the concentration range of $50 \%$ to $200 \%$ for Lead and Palladium, and of $12.8 \%$ to $200 \%$ for Zinc of specification level. From the regression analysis, the coefficient of determination $R^{2}$ was 0.9990 for all three analytes, indicating a linear relationship between the concentration of analyte and response under the peak. Linearity results for three analytes are shown in Table 7 and linearity graphs shown in Figs. 2, 3, and 4.

\section{Accuracy (recovery)}

Accuracy expresses the familiarity of conformity between the value obtained and the value which is accepted either as a predictable true value or an accepted reference value. The accuracy of the method is

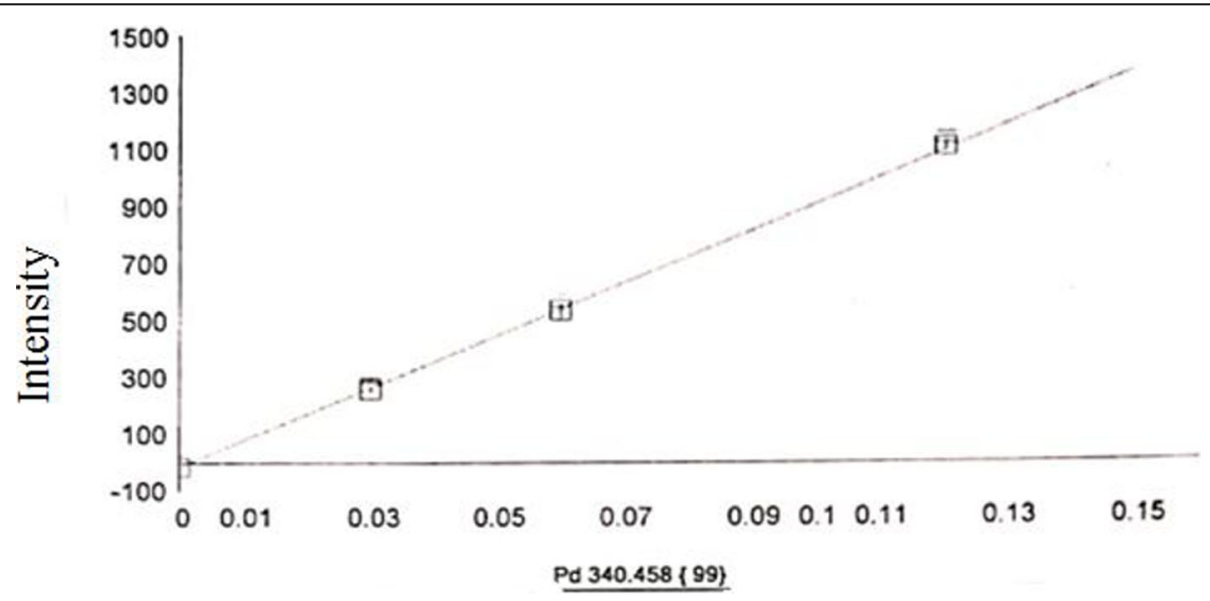

Fig. 6 Method precision representation of Palladium 


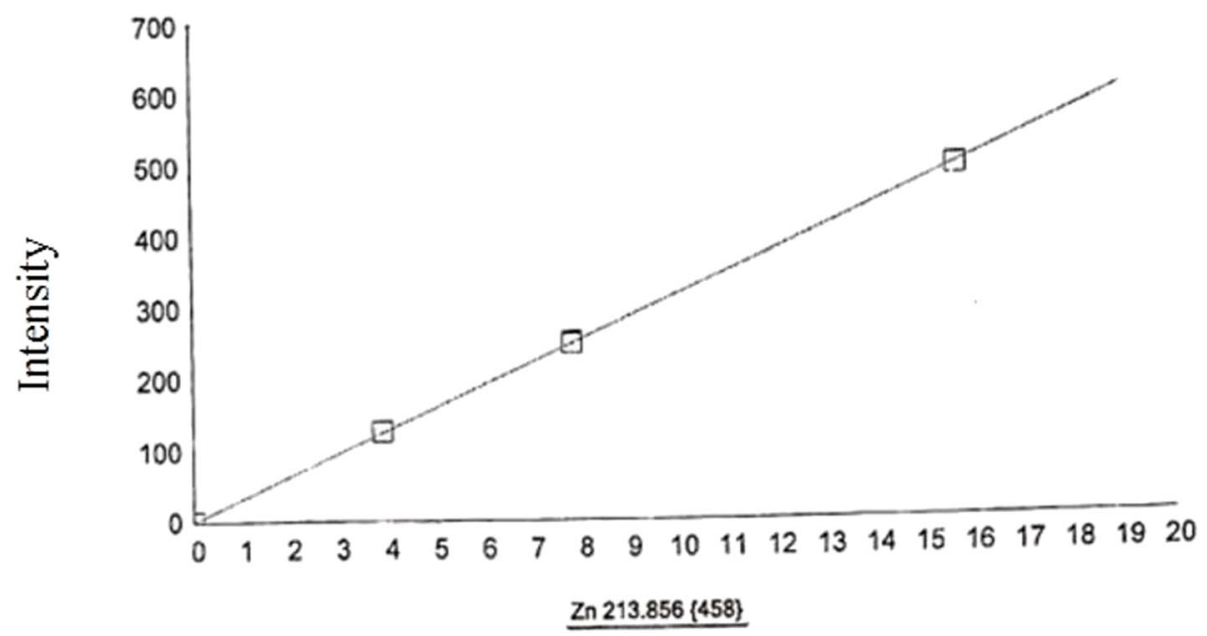

Fig. 7 Method precision representation of Zinc

determined by recovery studied for Lead, Palladium, and Zinc. The sample solutions were prepared in triplicate by spiking Lead, Palladium, and Zinc at LOQ level, 50\%, $100 \%$, and $150 \%$ of specification and analyzed individually as per test method. The percentage recovery of added Lead, Palladium, and Zinc and the $\%$ RSD were calculated for each replicate samples. Acceptance criteria is recovery should be between 70.0 and $150.0 \%$. Accuracy results tabulated below (Table 8).

\section{Precision (ruggedness)}

The closeness of agreement between a series of measurements obtained from multiple sampling of the same homogeneous sample under given conditions. The precision was checked both for system and method. System precision was demonstrated by aspirating standard solution of Lead, Palladium, and Zinc at LOQ level and measured six times. The requirement of acceptance criteria is \%RSD should not be more than 10.0.The results were within the acceptable criteria. The experimental system precision results are shown in Table 9.

\section{Method precision}

Method precision was determined by preparing six sample solutions individually using single batch of voriconazole drug substance spiked with Lead, Palladium, and Zinc at LOQ level and aspirated into ICP-OES as per methodology. Ruggedness was obtained by six sample solutions were prepared individually using single batch of voriconazole (used for method precision) spiked with Lead, Palladium, and Zinc at LOQ level and aspirated into ICP-OES as per methodology and determined Lead, Palladium, and Zinc contents using different analyst on different day. Acceptance criteria is \% RSD should not be more than $10.0 \%$ for method precision, ruggedness, and overall. Results were given in

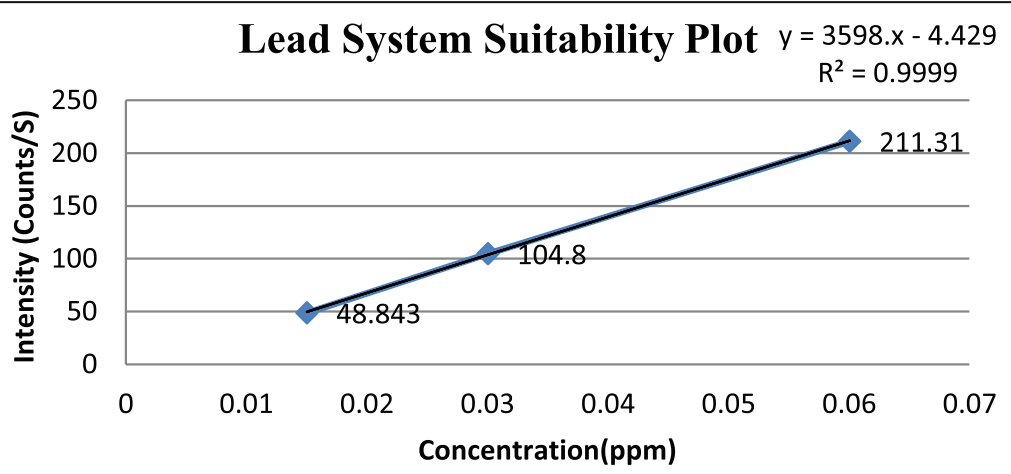

Fig. 8 System suitability plot of Lead 
Table 11 System suitability results of Lead

\begin{tabular}{|c|c|c|c|c|}
\hline S. No & Concentration (ppm) & Counts/S & Statistica & \\
\hline 1 & 0.01502 & 48.843 & Slope & 3599 \\
\hline 2 & 0.03003 & 104.8 & Intercept & -4 \\
\hline 3 & 0.06006 & 211.31 & STEYX & 1 \\
\hline \multicolumn{3}{|c|}{ Correlation co-efficient } & & 0.9999 \\
\hline
\end{tabular}

Table 10. Method precision spectra were shown in Figs. $5,6,7$, and 8 .

\section{System suitability}

A series of standard solutions of Lead, Palladium, and Zinc were prepared in the concentrations in the range for Lead (0.015 ppm, $0.03 \mathrm{ppm}$, and $0.06 \mathrm{ppm})$, Palladium (0.03 ppm, $0.06 \mathrm{ppm}$, and $0.12 \mathrm{ppm}$ ), and Zinc (3.9 ppm, $7.8 \mathrm{ppm}$, and $15.6 \mathrm{ppm}$ ) and aspirated to ICP-OES system as per methodology. From the linear solutions, correlation coefficient, Y-intercept, slope, and residual sum of squares (STEYX) were calculated, and thus the linear relationship of concentration vs Counts/S was verified over the range specified. Correlation coefficient results were 0.9999 for Lead, 0.9998 for Palladium, and 0.9999 for Zinc, respectively against acceptance criteria not less than 0.99 . Results were given in Tables 10, 11, and 12. Method precision spectra are shown in Figs. 9 and 10 .

\section{Discussion}

The research work focused on simple and rugged ICPOES method development and validation [30-34] of three elemental impurities, i.e., $\mathrm{Pb}, \mathrm{Pd}$, and $\mathrm{Zn}$, in voriconazole drug substance simultaneously. For the analysis of voriconazole, drug substance sample digestion was done using $2.5 \mathrm{ml}$ of hydrogen peroxide solution, $1.0 \mathrm{ml}$ of hydrochloric acid, and slowly $0.5 \mathrm{ml}$ of sulfuric acid. Among the three elemental impurities determined in voriconazole drug substance samples, one elemental impurity is class $1(\mathrm{~Pb})$, one impurity is class $2 \mathrm{~B}(\mathrm{Pd})$, and one impurity is class $4(\mathrm{Zn})$ according to the elemental impurities classification based on toxicity from $\mathrm{ICH}$ guidelines [13]. Till date, no ICP-OES method reported for the simultaneous determination of above three elemental impurities in any drug substance. So effort was through to develop simple, rapid ICP-OES method, and it was validated with LOD and LOQ $0.08 \mu \mathrm{g} / \mathrm{g}, 0.2 \mu \mathrm{g} / \mathrm{g}$, $5 \mu \mathrm{g} / \mathrm{g}$, and $0.25 \mu \mathrm{g} / \mathrm{g}, 0.5 \mu \mathrm{g} / \mathrm{g}, 16.7 \mu \mathrm{g} / \mathrm{g}$ for $\mathrm{Pb}, \mathrm{Pd}$, and $\mathrm{Zn}$ respectively. Linearity obtained was $0.9995,0.9990$, and 0.9997 for $\mathrm{Pb}, \mathrm{Pd}$, and $\mathrm{Zn}$ respectively. The average recovery found was $110 \%$ for $\mathrm{Pb}, 87.4 \%$ for $\mathrm{Pd}$, and $98.6 \%$ for $\mathrm{Zn}$. Determined concentrations of these analytes in drug substance samples were lower than the limits established by the chapter 232 [34]. In true sense, the daily maximum dose for voriconazole is $200 \mathrm{mg}$ and thus the risk is very little; therefore, the limits established considering this maximum daily dose are even elevated (Table 13).

\section{Conclusion}

ICP-OES method was developed and validated according to current ICH and FDA guidelines to quantify Lead, Palladium, and Zinc in voriconazole drug substance. The proposed ICP-OES method has been evaluated over the linearity, precision, accuracy, and specificity and proved convenient and effective for the quality control of voriconazole drug substance. Thus, the present study demonstrates that ICP-OES has the advantages over other conventional analytical methods for the determination of Lead, Palladium, and Zinc because of sensitivity, i.e., the lower limit of detection, for Lead, Palladium, and Zinc in voriconazole drug substance. Therefore, the method can easily be adopted for routine quantitative analysis of Lead, Palladium, and Zinc present as residual impurities in voriconazole drug substance.

Table 12 System suitability results of Palladium

\begin{tabular}{lllll}
\hline S. No & Concentration $(\mathbf{p p m})$ & Counts/S & Statistical analysis \\
\hline 1 & 0.03003 & 304.97 & Slope & Intercept \\
2 & 0.06006 & 587.93 & STEYX & 4 \\
3 & 0.12012 & 1190.1 & & 10 \\
Correlation Co-efficient & & & & 0.9998 \\
\hline
\end{tabular}




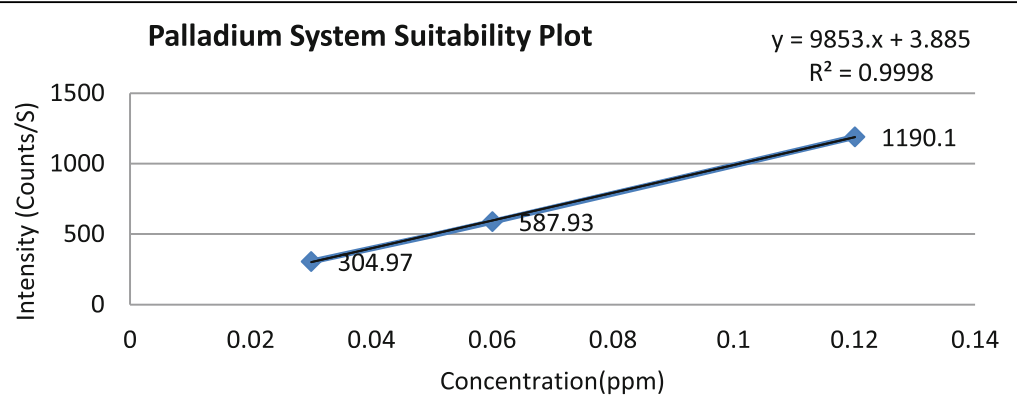

Fig. 9 System suitability plot of Palladium

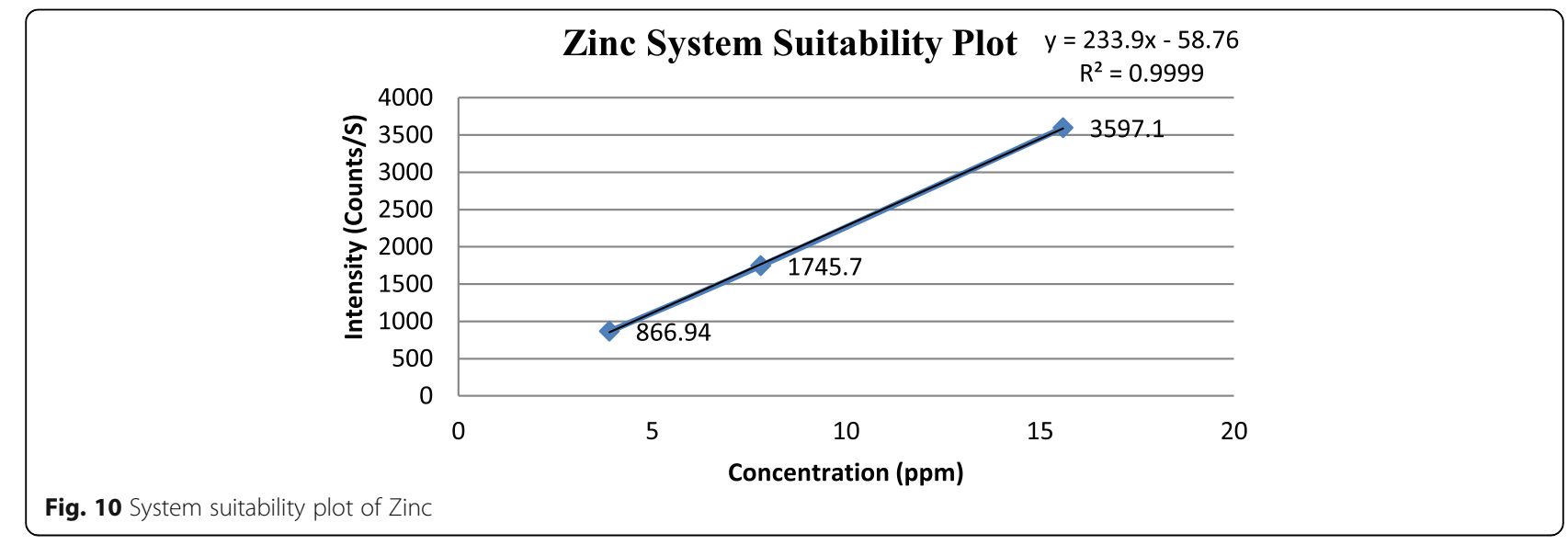

Table 13 System suitability results of Zinc

\begin{tabular}{lllll}
\hline S. No & Concentration(ppm) & Counts/S & Statistical analysis \\
\hline 1 & 3.9 & 866.94 & Slope & 234 \\
2 & 7.8 & 1745.7 & Intercept & -59 \\
3 & 15.6 & 3597.1 & STEYX & 25 \\
Correlation co-efficient & & & & 0.9999 \\
\hline
\end{tabular}




\section{Abbreviations}

LOD: Limit of detection; LOQ: Limit of quantitation; ICP-OES: Inductively coupled plasma optical emission spectroscopy; ICH: International Conference on Harmonization; FDA: Food and drug administration; $R^{2}$ : coefficient of determination

\section{Acknowledgements}

The authors gratefully acknowledge the management of APL Research Centre (A Division of Aurobindo Pharma Ltd., Hyderabad), for giving us the opportunity to carry out the present work. The authors are also thankful to the colleagues of Department of Chemistry, Andhra University.

\section{Authors' contributions}

MK performed the research work of the drug substance of Interest and TS as corresponding author executed the work. MK and JK prepared the manuscript and all authors (MK, TS, JK, CS, KS, KP) read the manuscript and approved

\section{Funding}

No funding.

\section{Availability of data and materials}

All data and material are available upon request.

\section{Ethics approval and consent to participate}

Not applicable.

\section{Consent for publication}

Not applicable.

\section{Competing interests}

No competing interests to declare.

\section{Author details}

${ }^{1}$ Aurobindo Pharma Limited, Survey No. 71\&72, Indrakaran Village, KandiMandal, Sangareddy, Telangana 502329, India. ²Department of Inorganic and Analytical Chemistry, AU College of Science and Technology, Andhra University, Visakhapatnam, Andhra Pradesh 530003, India.

\section{Received: 7 April 2020 Accepted: 15 December 2020}

\section{Published online: 15 February 2021}

\section{References}

1. Zhoua L, Glickmanb RD, Chenb N, Sponsel WE, Graybill JR, Lam KW (2002) Determination of voriconazole inaqueous humor by liquid chromatography-electrosprayionization-mass spectrometry. J Chromatogr B 776:213-220

2. Ray, S. J.; Richardson, K. (1994) U.S. Patent 5278175

3. Butters, M., Pettman, A. J. Harrison, J. A. (1997) W09706160.

4. De Sarro A, La Camera E, Fera MT (2008) New and investigational triazole agents for the treatment of invasive fungal infections. J Chemother 20(6): $661-671$

5. Purkins L, Wood N, Gharamani P, Greenhalgh K, Allen MJ, Kleinermans D (2002) A review of determination of voriconazole in human serum. Antimicrob. Agents Chemother. 46:2546-2550

6. Zhou L, Glickman RD, Chen N, Sponsel WE, Graybill JR, Lam KW (2002) A review of determination of voriconazole in human serum. J. Chromatogr. B: Anal. Technol. Biomed. Life Sci. 213:776-778

7. Keevil BG, Newman S, Lockhart S, Howard SJ, Moore CB, Denning DW (2004) A review of determination of voriconazole in human serum. Ther. Drug. Monit. 26:650-655

8. Perea S, Pennick G, Modak A, Fothergill A, Sutton D, Sheehan D, Rinaldi M (2000) Comparison of high-performance liquid chromatographic and microbiological methods for determination of voriconazole levels in plasma. Antimicrob Agents Chemother. 44:1209-1213

9. Owens PK, Fell AF, Coleman MW, Berridge JC (2002) Separation of the voriconazole stereoisomers by capillary electrophoresis and liquid chromatography. Enantiomer 4:79-90
10. Ferretti, R., Gallinella, B., La Torre, F. and Zanitti, L. (1998). A review on determination of voriconazole impurities by HPLC Chromatographia 47: $11-12$.

11. Srinubabu G, Raju CAl, Sarath N, Kumar PK, Rao JVLNS (2007) Development and validation of a HPLC method for the determination of voriconazole in pharmaceutical formulation using an experimental design. Talanta 71(3): 1424-1429

12. Cheng S, Qiu F, Huang J, He J (2007) Development and validation of a simple and rapid HPLC method for the quantitative determination of voriconazole in rat and beagle dog plasma. Journal of Chromatographic Science 45(7):409-414

13. International conference on harmonization of technical requirements for registration of pharmaceuticals for human use, guideline for elemental impurities, Q3D Step 4 (December 16, 2014).

14. Kielhorn, J., Melber, C., Keller, D., \& Mangelsdorf, I. (2002). Palladium-a review of exposure and effects to human health. International journal of hygiene and environmental health, 205(6), 417-432. https://doi.org/https:// doi.org/10.1078/1438-4639-00180

15. U.S. Department of Health and Human Services (2007) Toxicological profile for Lead (update). http://www.atsdr.cdc.gov/toxprofiles/tp13.pdfCdc-pdf (PDF 4901KB, 582 pages)] Public Health Service Agency for Toxic Substances and Disease Registry. https://doi.org/10.15620/cdc:95222

16. Fosmire GJ (1990) Zinc toxicity. Am. J. Clin. Nutr. 51(2):225-227

17. Saavedra R, Soto C, Gómez R, Muñoz A (2013) Determination of lead(II) by thermal lens spectroscopy (TLS) using 2-(2'-thiazolylazo)-p-cresol (TAC) as chromophore reagent. Microchemical Journal 110:308-313

18. Hauser, P. C. (2017). Analytical methods for the determination of lead in the environment. Lead - Its Effects on Environment and Health.

19. Zhai Q, Li J, Zhang JP (2013) Spectrophotometric Determination of Lead in Tea Leaf Sample with Dibromo-p-chloro-arsenazo. Asian J Chemistry 25(1): 538-540

20. Tokalioglu S, Oymak T, Kartal S (2004) Determination of palladium in various samples by atomic absorption spectrometry after preconcentration with dimethylglyoxime on silica gel Anal. Chim. Acta 511:255-260

21. Mori I, Kawakatsu T, Fujita Y, Matsuo M (1999) Selective spectrophotometric determination of palladium(II) with 2(5-nitro-2-pyridylazo)-5-(N-propyl-N-3sulfopropylamino)phenol(5-NO(2).PAPS) and tartaric acid with 5-NO(2).PAPSniobium(V) complex. Talanta 48:1039-1044

22. Shokrollahi A, Ramdar K (2017) Determination of trace amounts of palladium by solution scanometric method. J Taibah Univ Sci 11(5):782-787

23. Rajput, M.; Jain, V. K.; Hamid, H.; Aggarwal, M.; Khandal, R. K.(2014) Quantitative determination of platinum and palladium in donepezil hydrochloride using inductively coupled plasma â€" optical emission spectroscopy. Int J Pharm PharmSci, 7, 323-329.

24. Säbel CE, Shepherd JL, Siemann S (2009) A direct spectrophotometric method for the simultaneous determination of zinc and cobalt in metalloproteins using 4-(2-pyridylazo)resorcinol. Analytical Biochemistry 391(1):74-76

25. Säbel CE, Neureuther JM, Siemann S (2010) A spectro photometric method for the determination of zinc, copper, and cobalt ions in metalloproteins using Zincon. Analytical Biochemistry 397(2):218-226

26. Cherian L, Gupta VK (1991) A new spectrophotometric method for the determination of zinc in milk and standard samples. Water Air Soil Pollut 57:505-512

27. Moneeb MS (2006) Polarographic chemometric determination of zinc and nickel in aqueous samples. Talanta 70(5):1035-1043

28. Mamatha Veeramachaneni, Kumar Raja Jayavarapu (2013) Development and validation of new ICP-OES Analytical Technique to quantify the contents of Copper, Magnesium \& Zinc in "Escitalopram Oxalate, J Adv Pharm Edu Res vol 3(4),516-523.

29. ICH (2005) Validation of analytical procedures: methodology (Q2R1). International Conference on Harmonization, Food and Drug Administration

30. United States Pharmacopeia (2008) Ad hoc advisory panel on inorganic impurities and heavy metals and USP staff-stimuli to the revision process: general chapter on inorganic impurities: heavy metals

31. The United States Pharmacopeia Convention (2013), The United States pharmacopeia, Chapter 232: Elemental Impurities - Limits

32. European Pharmacopoeia, Chapter 5.20. Metal catalysts or metal residues. European Directorate for the Quality of Medicines. 2012. 
33. The United States Pharmacopeia Convention (2013) The United States Pharmacopeia, Chapter 233: elemental impurities-procedures, revision bulletin, Official February 1, 2013.

34. The United States Pharmacopeia Convention (2017) The United States Pharmacopeia, Chapter 232: Elemental Impurities - Limits, USP 40 - NF 35, First Supplement, Official December 1, 2017

\section{Publisher's Note}

Springer Nature remains neutral with regard to jurisdictional claims in published maps and institutional affiliations.

Submit your manuscript to a SpringerOpen ${ }^{\mathcal{O}}$ journal and benefit from:

- Convenient online submission

- Rigorous peer review

- Open access: articles freely available online

- High visibility within the field

- Retaining the copyright to your article

Submit your next manuscript at $\boldsymbol{\wedge}$ springeropen.com 